\title{
¿DE QUÉ MANERA LA MIGRACIÓN INTERNACIONAL PUEDE APOYAR EL DESARROLLO? UN DESAFÍO PARA FILIPINAS
}

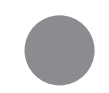

MARUJA M. B. ASIS

TRADUCCIÓN DE LUIS RODOLFO MORÁN QUIROZ

\begin{abstract}
Resumen. En los últimos treinta años, al acceder al mercado global de mano de obra como fuente de trabajo para sus ciudadanos, Filipinas acrecienta su importancia como país emisor de migrantes internacionales. Este artículo examina los factores y dinámicas que permitieron a este país, por un lado, promover la migración laboral y, por el otro, extender la protección a los trabajadores migrantes y en general filipinos en el extranjero. El papel del Estado se ha identificado como un elemento central para la institucionalización de la migración de mano de obra, al mismo tiempo que la actividad defensiva de la sociedad civil contribuyó a incluir los derechos de los migrantes en la formulación de políticas. El siguiente desafío para Filipinas es explorar de qué manera la migración internacional puede tornarse en un vehículo para promover el desarrollo sustentable.

Palabras clave: Migración internacional, política de migración laboral, trabajadores filipinos en el extranjero, remesas.

AвSTRACT. In the last thirty years, Filipinas has gained prominence as a major source country of international migrants. From modest beginnings, Filipinas has successfully managed to tap the global labor market as a source of employment for its nationals. This paper examines the factors and dynamics that enabled Filipinas to promote labor migration on the one hand, and to extend protection to migrant workers and overseas Filipinos on the other. The role of the state is identified as key in institutionalizing labor migration while advocacy by civil society contributed to the inclusion of migrants' rights in policy formulation. The next challenge for Filipinas is to explore how international migration may be a vehicle for promoting sustainable development. KEYWORDs. International migration, labor migration policy, overseas filipino workers, remittances.
\end{abstract}




\section{INTRODUCCIÓN}

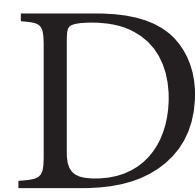

esde los años setenta, cuando comenzó a participar en la migración inter-

nacional, Filipinas ha sufrido un cambio notable. La diáspora filipina se ha elevado a ocho millones desde entonces, aproximadamente el $10 \%$ de la población total de 85 millones. ${ }^{1}$ En diciembre de 2005, los 7.9 millones de filipinos en el extranjero incluían a 3.7 millones de trabajadores, 3.4 millones de colonos permanentes y el resto eran migrantes en situación no autorizada. ${ }^{2}$ En comparación con otros migrantes de la región asiática, los migrantes Filipinos son heterogéneos en cuanto a ocupación, se distribuyen más ampliamente por el planeta y las mujeres migran tanto como los varones. Como trabajadores globales, los filipinos se han forjado un nicho en el trabajo doméstico, la marina (el 25\% de los marineros en el mundo son filipinos) y la enfermería.

Este artículo examina los factores y dinámica que subyacen al surgimiento de Filipinas como un importante país de origen de migrantes internacionales y el (futuro) papel de la migración internacional para contribuir al desarrollo nacional. Aunque los filipinos participan en diferentes formas de migración internacional, se enfatiza la prolongada experiencia en la migración laboral internacional. La primera parte describe los sistemas migratorios del este y el sureste asiáticos, lo que proporciona el contexto regional en el que se sitúa la experiencia migratoria de Filipinas. Las siguientes tres partes giran en torno a Filipinas. La parte dos comienza con una revisión de las tendencias y patrones de la migración internacional desde Filipinas a partir de los años setenta, discute los factores que desencadenaron y sostuvieron a la migración internacional, describe los procesos de institucionalización de la migración y describe las iniciativas para participar con la diáspora filipina. La parte tres presenta las cuestiones urgentes que la migración internacional ha generado en Filipinas, en particular aquellas relacionadas con el desarrollo. En la sección de conclusiones se reflexiona sobre las tendencias para el desarrollo: ¿será el futuro una simple extensión de la misma tendencia, es decir, salida continuada de los recursos humanos para el mercado de mano de obra mundial? ¿Qué otras opciones de política pueden explorarse para maximizar los impactos de la migración internacional en el desarrollo?

\section{EL ESTE Y EL SUDESTE ASIÁTICOS COMO}

\section{LUGARES DE MIGRACIÓN ${ }^{3}$}

Una vez terminada la Segunda Guerra Mundial y obtenida la independencia, los paí-

\footnotetext{
${ }^{1}$ Población estimada en junio de 2005 (NSCB, 2006: 11).

${ }^{2}$ Los cálculos provienen de un documento inédito de la Comisión para los Filipinos en el Extranjero.

${ }^{3}$ Los países y áreas del este de Asia considerados aquí incluyen: la República Popular China, Hong Kong SAR,
} 
ses asiáticos dedicaron sus energías a la reconstrucción y fortalecimiento de la nación. Entre 1945 y 1970, la migración internacional no mereció mucha atención en la vida regional. De acuerdo a esa visión hacia el interior, se discutió más la migración interna, en especial la creciente migración rural-urbana. No obstante, en los años setenta, los cambios económicos y políticos desataron procesos que promoverían la migración internacional en todas las regiones del planeta.

A partir de los setenta, el este y el sureste asiáticos se destacaron como regiones de origen, tránsito y destino de los migrantes internacionales. Asia se convirtió en una importante fuente de inmigrantes para los países tradicionales de establecimiento (Estados Unidos, Canadá, Australia y Nueva Zelanda) debido al criterio de separación por origen nacional en la admisión de nuevos inmigrantes. No obstante, con la aprobación de la Ley de Inmigración y Nacionalidad en Estados Unidos, en 1965, y las disposiciones similares adoptadas la década posterior en Canadá, Australia y Nueva Zelanda, el criterio favoreció a los inmigrantes con antecedentes en Europa occidental. La reunificación familiar, así como consideraciones humanitarias y laborales, conformaron la nueva base para la admisión de inmigrantes, lo cual propició una abultada inmigración procedente de Asia. La «nueva» inmigración, posterior al periodo que va de 1965 y la década de los setenta, alteró el perfil de las comunidades asiáticas en los países receptores. Las sociedades de solteros y la «vieja» oleada de inmigración cederían su lugar a comunidades asiáticas con mayor equilibrio en la distribución por sexos y con mayor diversidad ocupacional. Varios países asiáticos constituirían una parte significativa de la inmigración de ese continente hacia Estados Unidos, Canadá y Australia.

TABLA 1

Los 10 principales países de origen de los inmigrantes a Australia, Canadá y Estados Unidos

\begin{tabular}{|c|c|c|c|c|c|}
\hline & Australia, 2002 & & Canadá, 2000 & Estados Unidos, 2003 \\
\hline 1 & Reino Unido & 1 & China (excluye Taiwán) & 1 & México \\
\hline 2 & Nueva Zelanda & 2 & La India & 2 & La India \\
\hline 3 & China (sin Taiwán) & 3 & Pakistán & 3 & Filipinas \\
\hline 4 & La India & 4 & Filipinas & 4 & China (sin Taiwán) \\
\hline 5 & Sudáfrica & 5 & Corea del Sur & 5 & El Salvador \\
\hline 6 & Filipinas & 6 & Sri Lanka & 6 & República Dominicana \\
\hline 7 & Indonesia & 7 & Estados Unidos & 7 & Vietnam \\
\hline 8 & Irak & 8 & Irán & 8 & Colombia \\
\hline 9 & Sudán & 9 & Yugoslavia & 9 & Guatemala \\
\hline 10 & Malasia & 10 & Reino Unido & 10 & Rusia \\
\hline
\end{tabular}

Fuente: Asis (2005d: 10, tabla 1)

Japón, Taiwán y Corea del Sur. Los países del sureste asiático que se incluyen en el análisis de este capítulo son: Indonesia, Filipinas, Vietnam, Burma, Camboya, Laos, Tailandia, Malasia, Brunei y Singapur. 
La caída de Vietnam ante las fuerzas comunistas en 1975, seguida por acontecimientos similares en Camboya y Laos, derivaron en una abrumadora crisis de refugiados. Más de tres millones de personas salieron de Vietnam, Camboya y Laos en ese periodo, entre ellos, balseros que desesperadamente buscaban puertos más seguros. Se diseñó posteriormente el plan de acción global (Comprehensive Plan of Action, CPA) a fin de realizar un proceso más ordenado para el asentamiento de los refugiados y repatriación de quienes no lo eran. Cuando perdió vigencia el CPA, en 1997, cerca de 2.5 millones de personas se habían asentado en otros países y, de ellos, Estados Unidos recibió a más de un millón de refugiados; quinientas mil personas que no cubrían los requisitos como refugiados fueron repatriadas (Castles y Miller, 2003: 172). En las siguientes décadas se desataron otras migraciones de refugiados, pero estas salidas quedaron confinadas al interior de la región (por ejemplo, los refugiados de Burma huyeron a Bangladesh y Tailandia durante los años noventa y, más recientemente, de Corea del Norte a China), por ello, el reasentamiento dejó de ser una opción. Como en otras partes del mundo, la migración de refugiados se ha combinado con la migración no autorizada, situación que ha hecho que los refugiados se tornen más vulnerables y en desventaja.

En la región, la migración laboral internacional comenzó en la década de los setenta, a partir de la gran demanda de trabajadores en los países petroleros del Golfo Pérsico. El alza en los precios de petróleo en 1973 se convirtió en una "crisis petrolera» para el resto del mundo, pero fue un momento de bonanza para los países productores de petróleo. Con los petrodólares, los países del Golfo - Bahrein, Kuwait, Omán, Katar, Arabia Saudita y los Emiratos Árabes Unidos- reclutaron trabajadores asiáticos, con contratos, para llevar a cabo sus proyectos de infraestructura; era común que los contratos se extendieran por dos años, con posibilidades de renovación. Corea del Sur, Filipinas y Tailandia, además de los países del sur de Asia - Bangladesh, India y Pakistánrespondieron a la demanda de trabajadores. Indonesia y Sri Lanka entraron a escena más tarde, a tiempo para la demanda de trabajadores extranjeros en labores domésticas. Estos dos países se convirtieron en las principales fuentes de trabajadoras domésticas en el Medio Oriente. Las agencias de reclutamiento y los intermediarios intervinieron para «facilitar» la conexión entre trabajadores y patrones. Estas organizaciones y los negocios relacionados llegaron a ser conocidos como la «industria de la migración», que ha jugado un papel importante en la continuidad de la migración en la región. La culminación de los proyectos de infraestructura, en los años ochenta, alteró la demanda de trabajadores y atrajo a mujeres migrantes. Se reclutó personal de salud, vendedoras, dependientas, profesionistas, trabajadoras domésticas, afanadoras y trabajadoras en el sector de servicios. Años más tarde, otros países del oriente - Líbano, Jordania e Israel- también se convirtieron en países importadores de mano de obra. Décadas después, la región del Golfo sigue dependiendo de los trabajadores migrantes para el funcionamiento de sus industrias, negocios, servicios y hogares. Preocupados por su dependencia de trabajadores extranjeros, el desempleo creciente y el desequilibrio demográfico (por ejemplo, más del 70\% de la población de los Emiratos Árabes Unidos es extranjera), todos los países del Golfo han iniciado esfuerzos por la nacionalización 
de su fuerza de trabajo. El progreso ha sido lento. En particular, el sector privado en estos países seguirá dependiendo de los trabajadores migrantes por algún tiempo. A excepción de Corea del Sur, que se convirtió en un país importador de mano de obra en los años noventa, el resto todavía depende del Medio Oriente como importante destino para sus nacionales, en especial de los países del sur de Asia e Indonesia.

TABLA 2

Reservas de trabajadores extranjeros en los países receptores en el este y sureste asiáticos; información anual más reciente

\begin{tabular}{|c|c|c|c|c|}
\hline PAÍs & LEGAL [AÑO] & NO AUTORIZADA [AÑNO] & TOTAL & FUENTE(s) \\
\hline \multicolumn{5}{|c|}{ Sureste asiático } \\
\hline \multirow[t]{2}{*}{ Brunei } & 150000 & na & 150000 & Asian Migration News, \\
\hline & {$[2004]$} & & {$[2004]$} & $30 / 09 / 04$ \\
\hline \multirow[t]{3}{*}{ Malasia } & 1470000 & 400000 & 1870000 & citado en Bloomberg, 2005; \\
\hline & & \multicolumn{2}{|c|}{ (otras estims: 300,$000 ; 500,000$ ) } & Asian Migration News, \\
\hline & & & & $15 / 04 / 05 ; 31 / 03 / 05$ \\
\hline Singapur & 621000 & na & 612000 & citado en Orozco (2005) \\
\hline \multirow[t]{3}{*}{ Tailandia } & 1269074 & 400000 & 1669074 & Asian Migration News, \\
\hline & [2004] & {$[2004]$} & [2004] & $15 / 05 / 05$ \\
\hline & & 800000 & & Declaración oficial de \\
\hline Este asiático & & & & Thailand (2005) \\
\hline Hong Kong & 340000 & na & 340000 & citado en Orozco (2005) \\
\hline \multirow[t]{6}{*}{ Japón } & 1973747 & 219428 & 2193175 & La cifra de 2004 se cita en \\
\hline & {$[2004]$} & [2003] & {$[2003 / 2004]$} & Migration News, n.d. \\
\hline & & & & Ministry of Justice citado \\
\hline & & & & en Iguchi (2005) \\
\hline & 870000 & & 1089428 & Estimado por Iguchi (2005) \\
\hline & [2003] & & {$[2003]$} & \\
\hline \multirow[t]{2}{*}{$\begin{array}{c}\text { Corea del } \\
\text { Sur }\end{array}$} & 179000 & 199000 & 378000 & Migration News (2005) \\
\hline & [Abril 2005] & [Abril 2005] & [Abril 2005] & \\
\hline \multirow[t]{2}{*}{ Taiwán } & 312664 & 16000 & 328664 & \\
\hline & [Nov 2004] & [Nov 2004] & [Nov 2004] & \\
\hline \multirow[t]{2}{*}{ Total } & 6315485 & 1234428 & 7549913 & \\
\hline & 5211738 & 1634428 & 6846166 & \\
\hline
\end{tabular}

Notas: Para Japón, la cifra legal se refiere a la población extranjera registrada; la cifra sombreada se basa en la estimación de Iguchi (2005) de trabajadores extranjeros; las cifras para la migración no autorizada se refiere a quienes exceden sus estancia. Para Taiwán, los migrantes no autorizados se refiere a quienes se ocultan. Las cifras sombreadas son estimaciones alternativas.

Fuente: Asis (2005a:20, Tabla 1) 


\section{Migración laboral intra-regional}

Desde los años ochenta florecieron las economías exportadoras, primordialmente Japón, Hong Kong, Singapur, Corea del Sur y Taiwán. Malasia y Tailandia se unirían más tarde a este grupo de economías de alto rendimiento en la región. En su camino al desarrollo, estos países tuvieron que reclutar trabajadores provenientes de los vecinos países en desarrollo (Filipinas, Indonesia, Vietnam, Burma, Camboya y Laos) para laborar en los sectores sucios, difíciles y peligrosos que eran evitados por los trabajadores locales. Una creciente participación femenina en la fuerza de trabajo derivó en la escasez de personal médico en los nuevos países industrializados, lo que propició el reclutamiento de trabajadoras domésticas extranjeras y, de paso, contribuyó a la feminización de la migración laboral. De tal modo que la migración laboral en la región se distribuiría acorde al género: los migrantes masculinos reaccionaban a la escasez de mano de obra en los sectores «públicos» de la economía (construcción, manufactura, agricultura) y las mujeres migrantes respondían a la escasez de trabajadoras en el sector "privado», como el cuidado de las personas en los hogares (Asis, Huang y Yeoh, 2005).

Los países receptores en el este y el sureste asiáticos también adoptaron una política de migración laboral temporal que evitaba el establecimiento. Para asegurar que los trabajadores no se establecieran, la estancia de los trabajadores migrantes estaba limitada por contratos de dos años (que podían renovarse); los trabajadores no podían cambiar de sector o de patrón, y se prohibió la reunificación familiar (algunos países receptores no permiten el matrimonio con la población local; en el caso de mujeres migrantes, son repatriadas aquellas que sean identificadas como embarazadas). En un principio, los países de origen también concebían la migración laboral como algo temporal, pero más recientemente se proponen enviar a más de sus nacionales para que trabajen en el extranjero. Una vez desatada la migración intra-regional, se ha intensificado tanto la legal como la no autorizada, en especial en el este y el sureste asiáticos (Tabla 2).

\section{Migración no autorizada}

Aun cuando existe un marco legal para regular la migración laboral en la región, es considerable la migración no autorizada y existen significativas variaciones por país. Entre los países receptores, es más serio el problema en Malasia, Tailandia y Corea del Sur, mientras que está relativamente bajo control en Singapur, Brunei, Hong Kong, Japón y Taiwán (Asis, 2005a). Existen cuatro tipos de migrantes no autorizados: 1) trabajadores

\footnotetext{
${ }^{4}$ La migración no autorizada o irregular se refiere a «cualquier movimiento de población que viole los regímenes legales de migración, sea en el Estado de origen, tránsito o en el estado de destino» (IOM, 1999:4, citado por Battistella y Asis, 2003: 11).
} 
migrantes que carecen de permisos de trabajo (por ejemplo, un turista que se convierte en trabajador); 2) migrantes indocumentados son aquellos que carecen de documentos de viaje o de trabajo (cosa común en los flujos transfronterizos entre países vecinos, como Burma y Tailandia); 3) quienes exceden el tiempo establecido en sus permisos (overstayers), que entraron legalmente como trabajadores pero permanecieron en los países de destino después de que expiraron sus permisos de trabajo, y 4) los escapados o escondidos, que son trabajadores migrantes que huyen de sus patrones o patrocinadores, incluidos en este grupos quienes se escapan por las difíciles condiciones de trabajo o de vida. La distinción entre la migración legal y la no autorizada no es tan tajante como podría parecer. En el caso de los escapados, por ejemplo, los trabajadores migrantes pueden haber cumplido con los requisitos de entrada para obtener un permiso de trabajo, pero las duras condiciones del empleo pueden impulsarlos a dejar al patrón o patrocinador designado. Además, la migración no autorizada no es simplemente que los migrantes realicen prácticas no autorizadas; el papel de los patrones, intermediarios y agencias de reclutamiento e incluso las políticas de Estado deben ser objeto de examen. El estudio de la migración no autorizada en el sureste de Asia sugiere la importancia del contexto para entender los flujos transfronterizos en áreas con historias y fronteras compartidas, además de afinidades culturales: Indonesia con Malasia; Mindanao, Filipinas con Sabah, Malasia, y Burma con Tailandia. Los movimientos poblacionales en estas áreas tienden a ser más «regionales» que propiamente migración internacional, un hecho que ha de tomarse en consideración en el manejo de esos movimientos transfronterizos (Wong y Teuku Anwar, 2003, citados en Battistella y Asis, 2003). Los hallazgos del mismo estudio indican que la migración legal y la no autorizada se ven impulsadas, básicamente, por los mismos factores causales en los extremos de la oferta y la demanda: ambas son orientadas por mediadores e intermediarios. La principal diferencia se da en el acceso de los migrantes a canales legales o no autorizados (incluidos los contrabandistas y traficantes de personas). Las políticas migratorias deben tomar en cuenta, entonces, tanto la migración legal como la no autorizada de manera global, en vez de tratarlas como independientes y diferentes entre sí. ${ }^{5}$

La preocupación por la migración no autorizada desató discusiones regionales que comenzaron en la convención de Bangkok en 1999. La atención de la comunidad internacional en el tráfico, aunado a la mayor cantidad de recursos para la investigación y la acción en ese renglón, atrajo una mayor atención sobre el tema; el sureste asiático, en especial la subregión del amplio Mekong, constituyó el principal espacio para la investigación y la defensa. Después del 9/11, la migración no autorizada comenzó a ligarse

\footnotetext{
${ }^{5}$ Una comparación de la migración legal, no autorizada, el tráfico de personas y el contrabando de personas se detalla en Asis (2005). Esa comparación sugiere también que mientras que existen diferencias en los modos de migración, las formas de migración legal y no autorizada pueden tener resultados muy similares para los migrantes, independientemente de si son legales o no autorizados, es decir, las condiciones en el trabajo y en la forma de vida de los migrantes pueden ser muy similares en los migrantes legales o no autorizados, aunque el nivel de vulnerabilidad puede variar.
} 
con los temas de seguridad y, desde entonces, la discusión se ha orientado hacia temas como mayor control fronterizo, vigilancia, redadas y medidas similares. Las políticas y enfoques sobre la migración no autorizada deben revisarse, pero vincular esas reformas con la lucha contra el terrorismo ha generado un clima de desconfianza y hostilidad contra los migrantes. Al enmarcar a los migrantes como terroristas potenciales, resulta fácil que se dejen de lado los derechos de los migrantes, especialmente los derechos de los migrantes no autorizados y de las personas que han sido objeto de tráfico.

\section{Otros movimientos poblacionales}

La migración de personas altamente calificadas siempre ha sido parte de los movimientos poblacionales en la región, pero, dado su escaso número, se les ha pasado por alto. Desde los años noventa se han dado varios cambios. En primer lugar, se incrementó la cifra de migrantes con alta capacitación. En segundo lugar, mientras que Asia era una región de origen de los migrantes altamente calificados, lo que originaba preocupaciones por la fuga de cerebros, en los años noventa los países asiáticos más desarrollados comenzaron a competir con otros países desarrollados en la atracción de migrantes calificados. En tercer lugar, lo que antes se veía como «fuga de cerebros» comenzó a verse, en las discusiones más recientes, como transferencia de conocimientos y como «ganancia de cerebros» (Wescott, 2006).

Es probable que la migración de personas calificadas se incremente en el futuro. Los países de destino, en la región, se proponen atraer más migrantes calificados y los países de origen se avocan a proveer más migrantes calificados y profesionistas al extranjero. El auge de la industria de las tecnologías de la información y comunicación en India ofrece un ejemplo inspirador acerca de la manera en que la migración de personal calificado puede beneficiar a los países de origen. Mientras tanto, la migración de enfermeras plantea una nota de precaución, en particular porque es probable que impacte en la prestación de servicios de salud en los países de origen. Estos casos contrastantes parecen sugerir que el impacto de la migración de trabajadores altamente calificados, en los países de origen, podría depender de quién salga y de las posibilidades de transferencia o circulación de conocimientos y servicios.

La nueva prosperidad de los países asiáticos también ha incrementado la cifra de estudiantes que son capaces, por sí mismos, de financiar sus estudios y migrar a otros países para continuar su formación. La migración de estudiantes puede ser el preludio de otras migraciones en el futuro. Algunos países de destino, como Australia, están en busca de estudiantes extranjeros que hayan logrado un grado superior en sus propias instituciones como posibles inmigrantes calificados. El que los estudiantes no retornen a sus países de origen, puede ser una pérdida de recursos humanos calificados o, en el largo plazo, convertirse éstos en canales para la transferencia de conocimientos.

En la región se han incrementado los matrimonios internacionales, paralelamente a la migración. Antes de los años setenta, los matrimonios internacionales se realizaban entre mujeres asiáticas y hombres occidentales. Después de los setenta, los matrimonios 
internacionales en los que participan personas de origen asiático se han incrementado, es común que incluyan a mujeres de países menos desarrollados, que son, además, países de origen de trabajadores migrantes, con hombres de países más desarrollados, países que son también los destinos de los trabajadores migrantes. La migración, pues, emerge como una solución a la escasez de novias en países más desarrollados, como Japón, Taiwán y Corea del Sur. Los matrimonios internacionales han contribuido al incremento de la migración femenina. Los vínculos probables con el tráfico - como el tráfico de mujeres vietnamitas como novias de granjeros chinos-, la participación de intermediarios, el uso del matrimonio como un anzuelo para reclutar mujeres para la industria del sexo o para el trabajo, así como el uso del matrimonio para lograr el ingreso o la residencia en otro país, han provocado que se cuestione la autenticidad de estos matrimonios y el bienestar de dichas mujeres migrantes.

\section{Prospectos \\ para el futuro}

Hasta el momento, las tendencias apuntan a un incremento futuro en la migración internacional. Los diferenciales económicos y demográficos continuarán generando demanda, a la vez que factores de empuje, para sostener la migración. Lo más probable es que los factores del lado de la demanda asuman más importancia de la que han tenido en el pasado. Al enfrentarse con una población que decrece y a la vez se avejenta, la inmigración aparece como una de las posibles soluciones para los países de destino.

Aunque tanto los países de origen como los de destino prevén que, en el futuro, enviarán y recibirán trabajadores migrantes calificados, la demanda de trabajadores migrantes menos calificados no disminuirá. Los sectores de las «3D», incluido el del trabajo doméstico, tienen escasas probabilidades de atraer trabajadores locales. También es probable que la migración femenina persista, dado que la demanda de trabajadoras domesticas tiende a ser estable; la demanda futura de personal de cuidados en salud también incluirá a mujeres migrantes. Hasta el momento, las políticas en la región consideran a la migración básicamente como la transferencia de mano de obra y de capacitación. Se requiere ampliar los márgenes de la discusión y promover la cooperación a un nivel de mayor alcance regional para tratar los derechos de los migrantes, la responsabilidad compartida en la promoción de los derechos de los migrantes y una visión regional acerca de cómo la migración puede promover un desarrollo más equitativo.

\section{FILIPINAS:}

\section{¿UN EXITOSO PAÍS DE ORIGEN?}

Durante la mayor parte del siglo xx, hasta los años setenta, Estados Unidos era el principal país de destino de los filipinos que se aventuraban en la migración internacional. Como territorio de Estados Unidos, a los filipinos se les consideraba nacionales de 
Estados Unidos (pero no ciudadanos), lo que facilitaba la migración de trabajadores filipinos a Estados Unidos. ${ }^{6}$ El primer grupo de trabajadores filipinos llegó a Hawai el 20 de diciembre de 1906. Muchos más filipinos, hombres en su mayoría, fueron reclutados como trabajadores de las plantaciones en los años siguientes; muchos migraron después, desde Hawai, a la costa oeste del Pacífico. Entre 1906 y 1934 llegaron a Estados Unidos entre 120,000 y 150,000 filipinos, la mayoría de ellos se establecieron en Hawai. Algunos trabajadores regresaron a Filipinas. Quienes permanecieron en Estados Unidos constituyeron comunidades compuestas en su mayoría por solteros.

El parteaguas en la inmigración filipina a Estados Unidos y los otros países de establecimiento se dio tras las reformas migratorias. Filipinas se convertiría en una importante fuente de inmigrantes hacia estos países. Según datos de la Comisión de Filipinos en el Extranjero, entre 1981 y 2003, un promedio de 55,000 filipinos sale del país cada año como emigrantes permanentes.

\section{El contexto de los años setenta}

La imposición de la ley marcial el 21 de septiembre de 1972, por el entonces presidente Ferdinando Marcos, cambió el curso político y económico de Filipinas. La represión política durante el periodo de la ley marcial (1972-1981) derivó en migración hacia el exilio de figuras políticas que se oponían a Marcos. Muchos filipinos de clase media, ansiosos por sus prospectos de futuro, también salieron del país. Estas huidas tuvieron a Estados Unidos como destino principal, en donde continuaron luchando por la restauración de la democracia en Filipinas. Una nueva oleada de migración hacia el exilio y de huida de la clase media se dio tras el asesinato de Benigno Aquino Jr., el máximo crítico de Marcos, el 21 de agosto de 1983.

La ley marcial también contribuyó a desatar el desplazamiento de la población en Mindanao. El conflicto entre el gobierno y las fuerzas secesionistas alcanzó su apogeo con el incendio de Jolo, el cuartel del Frente Nacional de Liberación de Moro, en 1974. El episodio desembocó en un desplazamiento masivo; muchos huyeron a Sabah, Malasia, en donde se les reconoció como refugiados (Asis, 2005c; Abubakar, 1999). Esta bienvenida ya no fue la misma a fines de los años setenta, cuando Sabah consideró cada vez más a los recién llegados como migrantes económicos. ${ }^{8}$

\footnotetext{
${ }^{6}$ Filipinas fue cedida a España por Estados Unidos tras la guerra entre España y Estados Unidos. Bajo el Tratado de París, firmado entre España y Estados Unidos el 10 de diciembre de 1898, Estados Unidos compró Filipinas a España en 20 millones de dólares americanos.

${ }^{7}$ Quienes salieron del país durante esos periodos críticos de alguna manera fueron percibidos como desertores (Vergara, 1996; Aguilar, 1999), una visión que contrastaba notablemente con la celebración de los trabajadores por contrato en el extranjero (overseas contract workers-ocw’s) como los nuevos héroes.

${ }^{8}$ Los enfrentamientos entre las tropas del gobierno y los grupos musulmanes (incluido el grupo extremista Abu Sayyaf) siguen en pie y han derivado no sólo en un desplazamiento interno masivo sino que también han generado desplazamientos prolongados, algunas comunidades se han visto obligadas a desplazarse durante periodos que alcanzan incluso los 35 años (Canuday, 2006).
} 
Finalmente, la ley marcial interrumpió la marcha del país al desarrollo económico. El capitalismo de complicidad, es decir, las desiguales desventajas de que gozaban los cómplices y simpatizantes de Marcos y la difundida corrupción perjudicaron la alguna vez promisoria economía. Factores externos, como la crisis petrolera de 1973, contribuyeron a empeorar la situación económica nacional. Ello generó presiones hacia la emigración, las que afortunadamente coincidieron con la demanda de trabajadores en el Medio Oriente. Esta convergencia de fuerzas, los factores de empuje en Filipinas y los factores de atracción en el Medio Oriente, contribuyeron al ingreso de Filipinas en el mundo de la migración de mano de obra. ${ }^{9}$

Promulgado en 1974, el Código Laboral de Filipinas (Decreto presidencial DP 442) despegó el programa de migración laboral del país. El DP 442 anticipaba la creación del Consejo para el Desarrollo del Empleo en el Extranjero (Overseas Employment Development Board -ОЕDB) y el Consejo Nacional de Marineros (National Seamen Board -NSB) «para promover el empleo de filipinos en el extranjero y asegurarles los mejores términos y condiciones posibles de empleo» (Abella, 1978:24). Inspirados por el éxito de Corea del Sur para asegurar el logro de los proyectos de infraestructura, que utilizaban recursos y productos coreanos (trabajadores, conocimientos, materiales de construcción y envío), tanto el OEDB como el NSB estaban pensados para lograr el mismo resultado (Abella, 1978: 29-30).

\section{Migración laboral: los años posteriores}

La migración laboral, como anticipación de mejores prospectos económicos, solía concebirse como una medida temporal para atacar los problemas del desempleo galopante y de la balanza de pagos. En cambio, el traslado legal de trabajadores con bases de operación terrestres y marinas ha mostrado una tendencia al alza desde los años setenta (Tabla 3). La población de trabajadores filipinos en el extranjero constituye la mayor porción de la diáspora filipina (3.7 millones) y es la más dispersa geográficamente (véase también Tabla 4). El 21 de noviembre de 2006, se «celebró» otro parteaguas: el cumplimiento de la meta gubernamental de enviar fuera a un millón de trabajadores por año. Entre el primero de enero y el 21 de noviembre de 2006, se trasladó un total de 1'011,138 trabajadores. El establecimiento de esa meta es parte de la estrategia de generación de empleos del gobierno de Arroyo. ${ }^{10}$ En correspondencia, se han incrementado

\footnotetext{
${ }^{9}$ La salida de trabajadores migrantes varones de manera pública, formal y legal, en los años setenta, tuvo un paralelo en el movimiento menos visible y espontáneo de mujeres migrantes que accedían a empleos como trabajadoras domésticas hacia el sur de Europa (Italia, España y Grecia) en el mismo periodo (Asis, 2005b). La migración femenina se hizo más conspicua a partir de la década de los ochenta, cuando emigraron más mujeres filipinas como trabajadoras domésticas (y como parte de la industria del entretenimiento, en gran parte hacia Japón).

${ }^{10}$ Veronica Uy, «Filipino Deployment Abroad Exceeds 1M Target -Labor Dept», Philippine Daily Inquirer, 1 de diciembre de 2006, http://globalnation.inq7.news/view_article.php?article_id=35819, consultado el 1 de diciembre de 2006.
} 
las remesas (Tabla 3). En 2006, se esperaba que las remesas alcanzaran los 12 mil millones de dólares estadounidenses. Las remesas de los migrantes han contribuido en buena medida a la economía y, por ello, el Estado ha alabado a los trabajadores filipinos como los nuevos héroes del país (bagong bayani). ${ }^{11}$

TABLA 3

Salidas anuales de trabajadores filipinos por sector y remesas, $1975-2005^{*}$

\begin{tabular}{|c|c|c|c|c|}
\hline AÑO & BASE EN TIERRA* & BASE MARINA* & SALIDAS TOTALES ${ }^{*}$ & CANTIDAD $^{* *}$ \\
\hline 1975 & 12501 & 23534 & 36035 & 103.00 \\
\hline 1976 & 19221 & 28614 & 47835 & 111.00 \\
\hline 1977 & 36676 & 33699 & 70375 & 213.00 \\
\hline 1978 & 50961 & 37280 & 88241 & 290.85 \\
\hline 1979 & 92519 & 44818 & 137337 & 364.74 \\
\hline 1980 & 157394 & 57196 & 214590 & 421.30 \\
\hline 1981 & 210936 & 55307 & 266243 & 545.87 \\
\hline 1982 & 250115 & 64169 & 314284 & 810.48 \\
\hline 1983 & 380263 & 53594 & 434207 & 944.45 \\
\hline 1984 & 300378 & 50604 & 350982 & 658.89 \\
\hline 1985 & 320494 & 52290 & 372784 & 687.20 \\
\hline 1986 & 323517 & 54697 & 378214 & 680.44 \\
\hline 1987 & 382229 & 67042 & 449271 & 791.91 \\
\hline 1988 & 385117 & 85913 & 471030 & 856.81 \\
\hline 1989 & 355346 & 103280 & 458626 & 973.02 \\
\hline 1990 & 334883 & 111212 & 446095 & 1181.07 \\
\hline 1991 & 489260 & 125759 & 615019 & 1500.29 \\
\hline 1992 & 549655 & 136806 & 686461 & 2202.38 \\
\hline 1993 & 550872 & 145758 & 696030 & 2229.58 \\
\hline 1994 & 564031 & 154376 & 718407 & 2630.11 \\
\hline 1995 & 488173 & 165401 & 653574 & 4877.51 \\
\hline 1996 & 484653 & 175469 & 660122 & 4306.64 \\
\hline 1997 & 559227 & 188469 & 747696 & 5741.84 \\
\hline 1998 & 638343 & 193300 & 831643 & 7367.99 \\
\hline 1999 & 640331 & 196689 & 837020 & 6794.55 \\
\hline 2000 & 662648 & 198324 & 841628 & 6050.45 \\
\hline
\end{tabular}

\footnotetext{
${ }^{11}$ Muchos de los acontecimientos públicos se realizan en honor de los filipinos en el extranjero. Estos incluyen el domingo nacional de los migrantes (que se realiza el primer domingo de cuaresma; se trata de un día especial dedicado por la Iglesia Católica de Filipinas para recordar a los migrantes y sus familias), el 7 de junio es el día de los trabajadores migrantes (una fecha establecida por el gobierno para conmemorar la firma de la ley de los trabajadores migrantes y de los filipinos en el extranjero en 1995); el domingo de los marineros (celebrado el último domingo de septiembre) en honor de los marineros; diciembre es el mes de los filipinos en el extranjero (según se estableció en el Decreto 276, firmado por la presidenta Corazón Aquino el 21 de junio de 1988), y el 18 de diciembre es el día internacional de los migrantes (por iniciativa de las ONG's orientadas a la atención de los migrantes).
} 


\begin{tabular}{|c|c|c|c|c|}
\hline AÑo & BASE EN TIERRA & BASE MARINA $^{*}$ & SALIDAS TOTALES $^{*}$ & CANTIDAD $^{* *}$ \\
\hline 2001 & 662648 & 204951 & 867599 & 6031.27 \\
\hline 2002 & 682315 & 209593 & 891908 & 6886.16 \\
\hline 2003 & 651938 & 216031 & 867969 & 7578.46 \\
\hline 2004 & 704586 & 229002 & 933588 & 8550.37 \\
\hline 2005 & 733,970 & 247,707 & 981677 & 10689.00 \\
\hline
\end{tabular}

"Las cifras para 1975-1983 se refieren al número de contratosprocesados; las cifras para 19842004 refieren al número de trabajadores que salieron al extranjero. ${ }^{*}$ Cantidad en dólares de EUA (millones). Fuentes (Cols 1-3): Tabla 5 (Battistella, 1995: 265) para las cifras de 1975-1983; www.poea.gov.ph/doc/Depl;oyedOFWsByDestination1998.2003.xls para las cifras de 19832003; y www.poea.gov.ph/AR2004/AnnualReports/ar2004.pdf para datos de 2004. Las fuentes de Internet fueron consultadas el 12 de septiembre de 2005 y el 2 de mayo de 2006. Fuentes (Col 4): Tabla 5 (Battistella, 1995:265) para los datos de 1975-1994; www.poea.gov.ph/AR2004/ AnnualReports/ar2001.pdf para los datos de 1995 y 1996; y www.bsp.gov.ph/statistics/spei/ tab11.htm para los datos de 1997-2005. Las fuentes de Internet fueron consultadas el 12 de septiembre de 2005 y el 2 de mayo de 2006. Los datos para 1995 y 1996 son del reporte anual de la POEA de 2001.

La demanda de trabajadores migrantes, en particular la preferencia por los trabajadores filipinos, resulta significativa para sostener la migración de mano de obra. A medida que la demanda de trabajadores migrantes se expandió del Medio Oriente al este y sureste asiáticos, e incluso más allá de la región, Filipinas se las ha arreglado con éxito para extenderse hacia los mercados y sectores emergentes.

Los factores internos de Filipinas, sin embargo, son igualmente significativos (si es que no lo son más) para perpetuar la migración. Clasifico estos factores en tres grupos: factores persistentes de empuje, la institucionalización de la migración y el desarrollo de una cultura de la migración.

\section{- Factores de empuje}

Desde los años setenta, Filipinas ha pasado de una crisis económica a otra. En esa década fue la crisis del petróleo; en los ochenta, la economía se fue en picada a fines de los años del régimen de Marcos, además, la imposición de programas de ajuste estructural durante este periodo y los golpes militares, en los años posteriores a la caída de Marcos, impidieron que avanzara la economía y, en los noventa, la crisis económica en Asia y la inestabilidad política en el frente doméstico estancaron el crecimiento económico. En pocas palabras, el clima político y económico no ha favorecido las inversiones, cruciales para generar empleos. Al mismo tiempo, el país no es lo suficientemente pobre como para recibir ayuda para el desarrollo. El reto de generar empleos es especialmente abrumador debido al perfil demográfico de Filipinas (Tabla 5). La población del país alcanzó los 85 millones en 2005 y, dado que la población es joven 
(la mediana de edad es de 21.4 años), ello requiere de inversiones en formación de capital humano y enormes capacidades para la generación de empleos. En ausencia de desarrollo sostenible (Tabla 5), los factores de empuje continúan ejerciendo presión, en las familias y el país, para procurar empleo en el extranjero.

TABLA 4

Población filipina en el extranjero,

datos de reserva y flujo, 2005

\begin{tabular}{|c|c|c|c|c|c|}
\hline \multicolumn{6}{|c|}{ A. Reservas de población filipina en el extranjero, dic. 2005 } \\
\hline & REGIÓN/PAís & PERMANENTE & TEMPORAL & IRREGULAR & TOTAL \\
\hline & World Total & $3,391,338$ & $3,651,727$ & 881,123 & $7,924,188$ \\
\hline & América/Territ. de acuerdo & $2,758,067$ & 304,457 & 357,923 & $3,420,537$ \\
\hline & Estados Unidos & $2,326,675$ & 111,835 & 157,998 & $2,723,182$ \\
\hline & Asia, Oeste & 2,330 & $1,565,726$ & 112,750 & $1,680,806$ \\
\hline & Arabia Saudita & 244 & 976,427 & 18,000 & 994,671 \\
\hline & Asia, este y sur & 186,906 & 891,088 & 238,238 & $1,316,232$ \\
\hline & Japón & 114,980 & 139,791 & 30,619 & 285,390 \\
\hline & Europa & 211,351 & 523,442 & 123,282 & 858,075 \\
\hline & Reino Unido & 52,977 & 72,638 & 7,480 & 133,095 \\
\hline & Oceanía & 232,366 & 57,692 & 31,770 & 321,828 \\
\hline & Australia & 211,664 & 930 & 2,900 & 215,494 \\
\hline & África & 318 & 61,525 & 17,160 & 79,003 \\
\hline & Trabajadores con base marina & & 229,002 & & 229,002 \\
\hline
\end{tabular}

B. Diez principales destinos de los ofw con base en tierra

(Salidas, 2005)

\begin{tabular}{|c|c|c|l|l|l|}
\hline RANGO & & & & & \\
\hline 1 & Arabia Saudita & 193,991 & & & \\
\hline 2 & Hong Kong & 94,553 & & & \\
\hline 3 & Emiratos Árabes Unidos & 81,707 & & & \\
\hline 4 & Taiwan & 46,714 & & & \\
\hline 5 & Japón & 42,486 & & & \\
\hline 6 & Kuwait & 40,248 & & & \\
\hline 7 & Katar & 31,418 & & & \\
\hline 8 & Singapur & 27,599 & & & \\
\hline 9 & Italia & 21,261 & & & \\
\hline 10 & Reino Unido & 16,799 & & & \\
\hline & Total, base en tierra & 733,970 & & & \\
\hline & Total, base marina & 247,707 & & & \\
\hline
\end{tabular}

Fuentes: Los datos sobre la reserva de filipinos en el extranjero en 2005 son de un documento inédito de la Comisión para los filipinos en el extranjero; los datos sobre salidas de los ofw con base en tierra en 2005 provienen de la Philippine Overseas Workers Welfare Administration (www.poea.gov.ph/stats/2005/deployment.xls, consultada el 23 de mayo de 2006). 


\section{- La institucionalización de la migración}

El éxito de Filipinas para asegurarse un nicho en el mercado global de mano de obra no se dio por casualidad. Es crítico el papel del Estado para orientar al país por este rumbo. El código laboral de 1974 funcionó como cartabón para el programa, pero, a lo largo de los años, se han dado varias innovaciones, lo que ha desembocado en la institucionalización de la migración. Hasta el momento, Filipinas posee, probablemente, el marco institucional y legal más amplio para regular la migración internacional de su gente.

Existen agencias de gobierno diferentes para tratar con los migrantes permanentes y los trabajadores filipinos en el extranjero. La Comisión de Filipinos en el Extranjero (Commission on Filipinos Overseas - CFO), establecida en 1980, es la agencia que se encarga en primera instancia de los emigrantes y residentes permanentes en el extranjero (véase www.cfo.gov.ph). La CFO ofrece orientación y programas educativos para preparar a los emigrantes que están por partir, actividades entre las que se incluye un programa de guía y asesoría diseñado, específicamente, para las mujeres que migran al extranjero como novias o cónyuges de varones de otras nacionalidades. También se han desarrollado diversos programas para promover los lazos más estrechos entre los emigrantes y Filipinas. ${ }^{12}$

Varias agencias del gobierno participan en el programa de migración laboral: el Departamento de Trabajo y Empleo (Department of Labor and Employment-DOLE), el Departamento de Asuntos Exteriores (Department of Foreign Affairs -DFA), la Administración Filipina del Empleo en el Extranjero (Philippine Overseas Employment Administration -POEA) y la Administración del Bienestar para los Trabajadores en el Extranjero (Overseas Workers Welfare Administration -owwA). La owwa y la POEA son agencias del Departamento del Trabajo. Abajo se sintetizan las tareas y funciones de estas agencias:

\footnotetext{
- Creada en 1982, la poEA se integró y, luego, asumió las funciones del Consejo para el Desarrollo del Empleo en el Extranjero (Overseas Employment Development Board) del Consejo Nacional de Marineros (National Seamen Board). Vigila la concesión de licencias y la regulación de las agencias de reclutamiento y ubicación; administra las adjudicaciones relacionadas con las violaciones al proceso de reclutamiento; procesa
}

\footnotetext{
${ }^{12}$ El Programa Linkapil (Lingkod sa Kapwa Pilipino -Servicio a los compatriotas filipinos), conocido también como vínculo para el desarrollo de Filipinas (Link for Philippine Development), se desarrolló en 1989 para cotejar los donativos de los filipinos con las necesidades de las comunidades en Filipinas (www.cfo.gov.ph/linkapil.htm). En la actualidad, CFO negocia, ante el gobierno de Estados Unidos, a favor de las siguientes causas: derechos equitativos para los veteranos de guerra de origen filipino que prestaron sus servicios en la segunda guerra mundial, residencia permanente para 30,000-52,000 personas de origen americoasiático (hijos de soldados estadounidenses), la posibilidad de que se utilicen los beneficios de Medicare en Filipinas (para apoyar a los filipinos que residen en Estados Unidos que deseen retirarse en Filipinas), y la inclusión de Filipinas como centro de aplicación de exámenes para las enfermeras con reconocimiento del National Council Licensure Examination for Registered Nurses (NCLEX-RN).
} 
los documentos, contratos y permisos de empleo de los trabajadores filipinos que salen del país, y es responsable del desarrollo del mercado y la ubicación de trabajadores en la contratación de gobierno a gobierno.

- La owwa se desarrolló a partir del Fondo para el Bienestar (Welfare Fund), establecido en 1977. La owwa se encarga del bienestar de los trabajadores filipinos en el extranjero y de las familias que se quedan. Para apoyar a los trabajadores filipinos en el extranjero, administra los Centros de Recursos para los Filipinos en el Extranjero (Overseas Filipinos Resource Centres); envía a funcionarios del sector de bienestar a los principales países de destino para ayudar a los trabajadores filipinos en el extranjero con problemas relacionados con el bienestar, y es la agencia focal para los programas de reintegración. Recientemente se transfirió el Programa de Educación de los Trabajadores desde la poea a la owwa.

- El Departamento del Trabajo y Empleo (DOLE) envía agregados laborales a las misiones Filipinas en el extranjero; 34 Oficinas Laborales para los Filipinos en el Extranjero (Overseas Labor Offices -POLO’s) están presentes en varias regiones. Las POLO’s proporcionan asistencia sobre asuntos relacionados con el empleo y realizan estudios de mercado de mano de obra en su jurisdicción.

- El DFA representa la cara del gobierno ante los filipinos en el extranjero. Como se establece en el decreto sobre los trabajadores migrantes y los filipinos en el extranjero de 1995, «La protección de los trabajadores migrantes filipinos y la promoción de su bienestar en particular y la protección de la divinidad y los derechos y libertades fundamentales de los filipinos en el extranjero, en general, habrán de constituir la máxima preocupación de los puestos de la Secretaría de Asuntos Exteriores y del Servicio Exterior de Filipinas» (Secc. 72). El mismo decreto plantea también el establecimiento de una perspectiva de equipo por país en las misiones filipinas (Secc. 28) por medio de la cual «todos los funcionarios, representantes y personal del gobierno de Filipinas que se encuentre en el extranjero, independientemente de sus agencias de origen, habrá de actuar sobre la base del país y actuar como un equipo de un solo país con una misión bajo el liderazgo del embajador». Una oficina específica del DFA, la Oficina del Subsecretario para los Asuntos de los Trabajadores Migrantes (Office of the Undersecretary of Migrant Workers Affairs -OUMWA), ofrece ayuda legal y para la repatriación de los filipinos que encuentran dificultades durante su estancia en el extranjero.

Filipinas cuenta con elaboradas legislaciones, políticas y programas para promover que los migrantes puedan decidir y actuar por sí mismos (empowerment). También ha ratificado los instrumentos internacionales que protegen los de derechos de los migrantes.

Filipinas es el primer país de origen en Asia que ha establecido una ley, el decreto de los trabajadores migrantes y filipinos en el extranjero de 1995 (Acta de la República o RA 8042), con el propósito específico de proteger a su población migrante. ${ }^{13}$ A con-

${ }^{13}$ El título RA 8042 es «Un decreto para instituir las políticas de empleo en el extranjero y establecer un parámetro superior de protección y promoción del bienestar de los trabajadores migrantes, sus familias y filipinos que se 
tinuación se presentan algunas de las provisiones centrales dirigidas a proteger a los migrantes desde antes de su partida hasta su retorno a Filipinas:

- Limitar la salida de los trabajadores a países que aseguren protección y, si es necesario, prohibir la salida.

- Imponer duras penas a los reclutadores ilegales, incluidos los reclutadores legales que realicen prácticas consideradas irregulares. ${ }^{14}$

- Apoyo legal gratuito y programas de protección de testigos para las víctimas de reclutamiento ilegal.

- Ofrecer apoyo y asistencia a filipinos en el extranjero, estén en situación legal o no autorizada.

- Establecer la protección de los trabajadores migrantes filipinos y la promoción de su bienestar como la preocupación prioritaria del secretario de Asuntos Exteriores y los puestos de servicio diplomático de Filipinas.

- Establecer los centros de recursos para los trabajadores migrantes y los filipinos en el extranjero en países en donde haya un número considerable de filipinos.

- Crear la oficina del subsecretario de Asuntos para los Trabajadores Migrantes y el Fondo de Asistencia Legal.

- Instituir los servicios de consejería/información, repatriación y reintegración.

En un principio, el Estado promovió el empleo en el extranjero para resolver los problemas domésticos. A medida que se extendió la migración laboral, se multiplicaron los reportes de abusos en contra de los trabajadores. Desde los inicios del programa, los constantes reportes de reclutamiento ilegal y de prácticas irregulares estimularon, al Estado, a prohibir la participación de agencias de reclutamiento. Sin embargo, debido a la enorme demanda de trabajadores en el Medio Oriente, el Estado no tuvo otra opción que delegar el reclutamiento y la ubicación laboral en el sector privado. El Estado se limitó a regular y monitorear la industria de la migración (Asis, 1992). A medida que el mercado de mano de obra se tornó cada vez más en un mercado de adquisiciones y, con la participación de las mujeres en la migración de mano de obra, las dimensiones de bienestar de la migración laboral crecieron en magnitud. El trabajo de defensa y concientización de las onG's orientadas hacia los migrantes desempeñó un papel importante al plantear el tema de la protección de los trabajadores y hacer que el Estado fuera el responsable del bienestar de su pueblo.

encuentren en dificultades mientras estén en el extranjero y para otros propósitos». Se aprobó como ley el 7 de junio de 1995, unos cuantos meses después de que fuera ejecutada Flor Contemplación en Singapur, en marzo de 1995. Contemplación era una trabajadora doméstica a la que se encontró culpable del homicidio de un joven de Singapur y de otra filipina, Delia Maga. Muchos filipinos creían que ella era inocente y que había sido víctima de la desatención del gobierno por los trabajadores filipinos en el extranjero.

${ }^{14}$ Esta medida ha sido cuestionada por las agencias de reclutamiento. Además, las agencias de reclutamiento presionan para lograr que se reduzca la regulación de la migración laboral, lo que haría que el empleo en el extranjero fuera un asunto entre trabajador y patrón. Ambas reformas han encontrado oposición en el sector de las ONG's. 
La entrada en vigor de la ley de los trabajadores migrantes y de los filipinos en el extranjero, en 1995 (RA 8042), es más importante por lo que significó que por lo que realmente logró. Aun cuando la RA 8042 tiene algunas limitaciones fundamentales y provisiones contradictorias, ${ }^{15}$ establece la protección del trabajador migrante filipino como su máxima prioridad. Como establece la sección 2(a), «En la búsqueda de una política exterior independiente y considerando la soberanía nacional, la integridad territorial, el interés nacional y el derecho a la autodeterminación como primordiales en las relaciones con otros estados, el Estado está obligado en todo momento a salvaguardar la dignidad de sus ciudadanos, ya sea en el país o en el extranjero, en general, y de los trabajadores migrantes de origen filipino en particular». La RA 8042 establece también en la sección 2(c) que el Estado «no promueve el empleo en el extranjero como una forma de sostener el crecimiento económico y de lograr el desarrollo nacional. La existencia del programa de empleo en el extranjero se basa únicamente en la convicción de que la dignidad y los derechos y libertades humanos fundamentales del ciudadano filipino no han de comprometerse o violarse en ningún momento».

Además de la RA 8042, Filipinas aprobó otras leyes para proteger los derechos de los migrantes:

- Filipinas es uno de los pocos países en la región que cuenta con una ley, la ley en contra del tráfico de personas de 2003 (Anti-Trafficking in Persons Act), que establece políticas y mecanismos institucionales para dar apoyo a personas que hayan sido objeto de tráfico.

- El Estado dio un paso adicional al conceder a los ciudadanos filipinos en el extranjero el derecho al voto. La ley del voto ausente (Absentee Voting Act) de 2003 (RA 9189) 16 permite a los filipinos, que cumplan con los requisitos, que voten en las elecciones nacionales (presidente, vicepresidente, senadores y diputados de partido). ${ }^{17}$

- Otro paso para ampliar la acción del Estado para los filipinos en el extranjero fue la aprobación del decreto de ciudadanía y retención de los filipinos (Philippine Citizenship and Retention Act - RA 9225), en 2003, ${ }^{18}$ que concede a los filipinos que han accedido a otra ciudadanía el derecho a asumir nuevamente la ciudadanía filipina. ${ }^{19}$

\footnotetext{
${ }^{15}$ Para los detalles acerca de las provisiones en conflicto (Battistella, 1995; PMRW, 2003).

${ }^{16}$ El título de la ley es «Un decreto que propone un sistema de votos en ausencia por parte de los ciudadanos filipinos en el extranjero que cumplan con los requisitos, que incluye la asignación de fondos para ello y para otros propósitos». Se aprobó como ley el 13 de febrero de 2003, después de más de una década de cabildeo.

${ }^{17}$ Se registraron unos 364,000 filipinos ubicados en el extranjero; filipinos localizados en el medio oriente, África y en el Asia del Pacífico, es decir, en su mayoría trabajadores migrantes, los que alcanzaban el $86 \%$ de todos los filipinos registrados en el extranjero; los que se ubicaban en las Américas alcanzaban el $4 \%$ del total de los registrados. El 65\% (233,092) votó en las elecciones de mayo de 2004 (www.dfa.gov.ph/news/pr/pr2006/budget/2005/ oavdual.pdf, consultada el 30 de abril de 2006).

${ }^{18}$ El título es «Un decreto que hace que la ciudadanía de los filipinos sea permanente para aquellos que asumieron una ciudadanía extranjera, que reforma según los propósitos del decreto de la comunidad No. 53, también reformado para otros propósitos». Se aprobó como ley el 29 de agosto de 2003.

${ }^{19}$ En diciembre de 2005 se habían aprobado unas 14,600 solicitudes de doble ciudadanía, de las cuales, el 37.1\% provenía del continente americano (incluida Guam) (www.dfa.gov.ph/news/pr/pr2006budget/2005/oavdual.pdf, consultado el 30 de abril de 2006).
} 
- Filipinas ha ratificado los siguientes instrumentos internacionales: la convención de 1951 en relación con el Status de los Refugiados, el Protocolo de 1976 en relación con el Status de los Refugiados, la Convención Internacional para la Protección de los Derechos de todos los Trabajadores Migrantes y sus Familias, de 1990; el Protocolo de 2000 para Prevenir, Suprimir y Castigar el Tráfico de Personas, en Especial Mujeres y Niños; el Protocolo de 2000 en Contra del Contrabando de Migrantes por Tierra, Mar y Aire. ${ }^{20}$ También se han ratificado las convenciones de ILo números 97 (Convención de la Migración en busca de Empleo) y 143 (Provisiones -Suplementarias- sobre los Trabajadores Migrantes). ${ }^{21}$

En pocas palabras, el Programa de Empleo en el Extranjero ha contribuido a generar una amplia burocracia, aprobar varias legislaciones notables y desarrollar los marcos legales y de política para abordar los diversos aspectos del programa. En general, el enfoque parece ser el correcto. Sin embargo, desde el punto de vista de las onG's y las asociaciones de migrantes, el cuadro está lejos de haber logrado la perfección. Hay notables lagunas entre, por un lado, la legislación y las políticas, así como la vigilancia y las realidades cotidianas, por el otro. El amplio programa que se propone proteger a los migrantes en todas las etapas del proceso migratorio, desde antes de la salida, pasando por los problemas del lugar de llegada y desembocar en la reintegración, se ve limitado por la falta de recursos para una efectiva aplicación de sus provisiones. Un área del programa que requiere cambios y un nuevo diseño radical es la correspondiente a la reintegración. A causa de la escasez de oportunidades económicas en Filipinas, el trabajo temporal en el extranjero se ha convertido en la fuente de facto del empleo para muchos filipinos. Los migrantes, pues, alargan su estancia de empleo en el extranjero cuanto les sea posible. El que no se logre un desarrollo adecuado es la causa de que las personas salgan del país y es también la razón de que los trabajadores migrantes no regresen definitivamente a Filipinas.22

\section{- Cultura de la migración \\ Después de más de tres décadas de migración a gran escala, los filipinos se han conver- tido en un pueblo bastante familiarizado con la movilidad. Además de la diáspora fili-}

\footnotetext{
${ }^{20}$ Filipinas se encuentra entre los 143 estados que forman parte de la Convención de Refugiados de 1951 y de su Protocolo de 1967; está entre los 97 y los 89 estados que forman parte de los protocolos de tráfico y de contrabando del 2000, respectivamente (UN, 2006: 78). El 22 de enero de 2007, forma parte de los 35 países que han ratificado la Convención de los Trabajadores Migrantes de 1990 (www.december18.net, consultada el 31 de enero de 2007).

${ }^{21}$ Filipinas se encuentra entre los 21 países que han ratificado el c143 (www.ilo.org/ilolex/cgi-lex/ratifce.pl?c143, consultada el 1 de diciembre de 2006). Se informa que Filipinas ha ratificado el c97, pero todavía no se encuentra en la lista de estados partícipes del ILo (www.ilo.org/ilolex/cgi-lex/ratifce.pl?c097, consultada el 1 de diciembre de 2006 y 31 de enero de 2007).

${ }^{22}$ Un ejemplo de una práctica correcta es el programa de entrenamiento y sostenimiento vital de la red de mujeres para la acción orientada al desarrollo (Development Action for Women Network-DAWN) dirigida a las mujeres que antes se dedicaban a la industria del entretenimiento en Japón, un medio que se proporciona como alternativa a la migración (www.dawnphil.org).
} 
pina de ocho millones de personas, muchos de quienes siguen en el país ya piensan en migrar. Una encuesta de alcance nacional entre los filipinos adultos, realizada en 2005, reveló que un número creciente de filipinos —el 26\% en julio, el 33\% en octubre- estaba de acuerdo con la siguiente afirmación: «Si me fuera posible, emigraría a otro país y viviría ahí». Incluso los hijos tienen planes de salir a trabajar al extranjero algún día. En una encuesta nacional aplicada a los niños de entre 10 y 12 años de edad, el 47\% declaró que tenía planes de trabajar en el extranjero algún día; el porcentaje es más alto y alcanza el 60\% entre los hijos de migrantes (ECMI/AOs-Manila, SMC y OwwA, 2004).

Aparte del papel del Estado para facilitar la migración, otras instituciones en la sociedad filipina se han convertido en expertas en migración y apoyan los sueños de migración de los filipinos. Una de esas instituciones es la industria de la migración. Hay más de mil agencias autorizadas de reclutamiento para trabajadores con bases en tierra y otras 300-400 agencias para el manejo del sector de la marinería. Las prácticas ilegales de las agencias autorizadas y los abusos descarados de los intermediarios no autorizados han significado importantes costos para los migrantes y sus familias. El sistema educativo, en particular la comercialización de la educación en el país, es uno de los principales responsables de la demanda en el mercado global de mano de obra, al ofrecer planes de estudio y programas de instrucción que prometen generar trabajadores bien entrenados en un tiempo excesivamente corto. En un medio muy orientado a salir del país, el proponer que se puede llevar una buena calidad de vida en el país resulta un reto formidable.

PROS Y CONTRAS DE LA MIGRACIÓN INTERNACIONAL

Los impactos no económicos de la migración internacional, en la sociedad y las instituciones de Filipinas, han sido objeto de especulación por muchos años. Las discusiones acerca de las ramificaciones sociales, culturales y políticas de la migración tienden a teñirse de ambivalencia, inquietud y preocupaciones. Los temores en cuanto a los impactos negativos de la migración internacional en la familia han llamado notablemente la atención. La separación por lapsos prolongados entre los miembros de las familias genera el temor de que se erosione la estabilidad de la unidad familiar, plantea preocupaciones en torno a las relaciones en los matrimonios y entre padres e hijos. La participación de la mujer, en especial las que son madres, en la migración laboral se ha topado con una alarma más significativa que en el caso de la migración masculina. En primer lugar, la concentración de las mujeres en el trabajo doméstico y la industria del entretenimiento generó ansiedad en cuanto a su seguridad y bienestar. En segundo lugar, la preocupación por las familias, en especial por el bienestar de los hijos más jóvenes, evocaría las imágenes de los escenarios más pesimistas de niños abandonados, delincuencia y deserción escolar.

Los años setenta fueron una época en que el patrón típico de la migración impli- 
caba que ésta fuera masculina y las familias, por lo general, se ajustaban bien porque las mujeres que se quedaban asumían las responsabilidades de los padres migrantes. Cuando comenzaron a migrar las mujeres y quienes se quedaban eran los hombres, los estudios hicieron notar que los padres no necesariamente asumen los papeles de cuidado de la familia de las madres que migran, en cambio, dichos roles se pasaban a las otras mujeres de la familia. Cuando las mujeres salen, las familias atraviesan por más ajustes. En general, aun cuando la migración ha ampliado los roles de las mujeres, no ha tenido, como consecuencia, cambios fundamentales en los roles de género de la familia (Parreñas, 2005). En cuanto a los impactos más amplios de la ausencia de los padres en los hijos que se quedan, el estudio de los hijos y las familias realizado en 2003, en Filipinas, develó que los hijos de migrantes tienen un desempeño bueno o incluso mejor que el de los hijos de los no migrantes, en lo que se refiere a los indicadores de desempeño escolar y de salud. Los hijos de migrantes tienden a asistir a escuelas privadas y participar más en las actividades extracurriculares. Las remesas, entonces, se utilizan para invertir en la educación de los hijos (ECMI/AOs-Manila, SMC y owwA, 2004; Asis, 2006a; 2001).

A pesar de la separación de los miembros de la familia, ésta continua como un importante punto de referencia para los hijos, los padres migrantes así como los que se quedan y se encargan de cuidar a los hijos (Asis, Huang y Yeoh, 2005). Aunque no ha disminuido la importancia de la familia, las prácticas de «ser familia» se han modificado debido a la separación de los miembros de la familia. Los hijos de migrantes siguen viendo a sus padres como los modelos a seguir. Los avances en la tecnología de la comunicación han ayudado inmensamente para mantener los lazos familiares, aun cuando los miembros de la familia reconocen que la comunicación no es un sustituto adecuado de la presencia. En un sentido amplio, los datos de la encuesta muestran que los hijos y las familias se ajustan a la migración. Empero, los datos cualitativos revelan que los costos emocionales para los hijos, los migrantes y quienes se quedan al cuidado de los hijos no son despreciables (ECMI/AOs-Manila, SMC y owwA, 2004).

Los impactos económicos de la migración internacional se aprecian, con mayor facilidad, en particular en el nivel de las familias y los hogares. Dado que las remesas constituyen transferencias privadas, las familias y los hogares son los que se benefician directamente de ellas. Los usos típicos de las remesas incluyen la compra de tierra, la construcción o remodelado de las casas, pago de los costos de la escuela para los miembros de la familia, en especial de los hijos, el emprender pequeños negocios, compra de artículos de consumo duradero y el ahorro. Los hallazgos de los estudios confirman que las remesas se traducen en mejores condiciones materiales para las familias de los migrantes. En encuesta de alcance nacional, los hijos de los migrantes reportaron mayores índices como propietarios de casa y de bienes duraderos de consumo en comparación con los hijos de los no migrantes (ECMI/AOs-Manila, sMC y OwWA, 2004). A pesar de eso, el impacto de las remesas fuera de la familia no queda tan claro: de hecho, se ha generado preocupación respecto a la creciente desigualdad entre los hogares de los migrantes y los no migrantes así como cierta inquietud en torno al materialismo, el consumo suntuario, el despilfarro de las remesas y la dependencia que las remesas generan en las familias. Los hallazgos de la investigación indican que las familias de 
los trabajadores filipinos en el extranjero (OFW) suelen hacer buen uso de las remesas (Asis, 2006c)

Estudios pioneros recientes, que han explorado los potenciales de la migración para el desarrollo, sugieren que las remesas colectivas, por parte de los filipinos en el extranjero, contribuyen al desarrollo local (Baggio y Asis, 2006; Powers, 2006; Ateneo Center for Social Policy, 2005; Opiniano, 2005; Maas, 2005; www.filipinodiasporagiving.com). Los filipinos en el extranjero se han agrupado en unas 4,000 a 12,000 organizaciones (Bagasao, 2005, citado en Powers, 2006:16). Estas organizaciones incluyen asociaciones de oriundos (hometown associations), grupos organizados según su provincia/región/grupo étnico, familia o clan, asociaciones de ex alumnos, organizaciones de profesionistas, clubes deportivos, con sede en su credo o templo, sindicatos de trabajadores manuales, grupos temáticos con páginas electrónicas en la web, federaciones de asociaciones de migrantes y otras. Según la base de datos de las 129 organizaciones en el extranjero enlistadas en el portal de la diáspora filipina (www.filipinodiasporagiving. org), una abrumadora mayoría (99 de 129) tienen su sede en Estados Unidos y Canadá, unas 25 en Europa y, el resto, se distribuyen en otras regiones (Powers, 2006: 17). La mayor parte de las asociaciones de migrantes se han formado con propósitos distintos de la promoción o el apoyo de los esfuerzos orientados al desarrollo en el país de origen. No obstante, están abiertas a la idea de contribuir a las metas del desarrollo. En épocas de desastres, por ejemplo, las asociaciones de migrantes han movilizado recursos rápidamente para apoyar los esfuerzos de rescate en su país. Algunos migrantes o grupos de migrantes han apoyado algunos proyectos en Filipinas por iniciativa propia, por ejemplo, misiones de salud y otros proyectos humanitarios. Los migrantes y sus asociaciones también han recibido, con beneplácito, la idea de apoyar las festividades, los proyectos o programas comunitarios, cuando se les pide (Baggio y Asis, 2006). Los diversos modos de cooperación entre las asociaciones de migrantes y algunas instituciones, en Filipinas, se describen en Opiniano (2005).

Aparte del programa gubernamental para vincular las donaciones de los filipinos en el extranjero con las necesidades de desarrollo de las comunidades en Filipinas, hay iniciativas de varias ONG's, por ejemplo, para promover programas de ahorro entre los migrantes para apoyar a comunidades de migrantes o para preparar a los migrantes para su retorno (www.unladkabayan.org, www.atikha.org), además de la participación del sector privado (Asis, 2004)

\section{CONCLUSIÓN}

Una de las conclusiones que surge del informe de la Comisión Global sobre Migración Internacional (GCIM) para 2005 y del informe del secretario general Kofi Annan a la Asamblea General de la onu (publicado el 6 de junio de 2006) es la necesidad de abocarse a descubrir los potenciales de desarrollo de la migración internacional. Filipinas, con su amplia experiencia migratoria, es un país que requiere «forjar un vínculo entre la migración y el desarrollo» (GCIM, 2005: 24). Se trata de una historia con un final feliz, 
en el sentido de haberse convertido en una fuente primordial de trabajadores y de personal calificado en el mercado global de mano de obra. Filipinas puede considerarse, también, como un país exitoso en su promoción de prácticas adecuadas para promover que los migrantes sean capaces de dirigir sus propios avances como migrantes (migrant empowerment). En respuesta, los altos salarios de los trabajadores filipinos, su acceso a apoyos y su nivel de manejo de sus propias decisiones se traducen, además, en un mayor poder económico. Filipinas también ha tenido éxito en términos de los flujos de remesas enviados por su población en el extranjero. Pero, más allá de la movilidad social que han experimentado las familias de los migrantes y los proyectos comunitarios que han apoyado las remesas colectivas de los migrantes, los impactos de la migración en el desarrollo no son tan notables. La migración puede ser una de las muchas estrategias para promover el desarrollo (específicamente, la generación de empleos), pero no es suficiente como estrategia de desarrollo primordial. Ninguno de los países asiáticos que hicieron la transición entre el papel de país de origen al papel de país de destino lo ha logrado con base en el ímpetu aportado por las salidas de trabajadores o de las remesas (Asis, 2006c).

Ciertamente, el impulso para que se perpetúe la migración es bastante considerable y Filipinas podría «encasillarse» en el papel de productor de trabajadores para el mundo. Como se mencionó antes, el salir del país ha sido parte de los planes de vida de los filipinos. Incluso los niños se interesan en el trabajo en el extranjero y se inclinan a seleccionar trayectorias que los preparen para el mercado global de mano de obra (ECMI/AOS-Manila, SMC y OWwA, 2004). Los adultos jóvenes también están en busca de prospectos laborales en el extranjero, independientemente de los antecedentes migratorios de sus familias (Asis, 2006b). El ejemplo de la emigración de enfermeras ilustra el espinoso asunto de respetar las decisiones personales y tratar con los impactos sociales. La renovada demanda de enfermeras se fortalece por las decisiones que realizan individuos y familias en torno a la educación. Han proliferado los programas de enseñanza de enfermería como respuesta a la creciente demanda. Un desarrollo interesante es el fenómeno de los «segundos cursos», es decir, quienes han alcanzado su título universitario y que toman un segundo curso para aumentar su probabilidad de trabajar en el extranjero. El caso de los doctores que se enlistan en los programas de enfermería enfatiza los esfuerzos que las personas están dispuestos a realizar para estar en condiciones de trabajar en el extranjero.

Si estas tendencias no se controlan de algún modo, podrían tener como consecuencia que Filipinas tenga un superávit de enfermeras que podrían acabar desempleadas. La concentración en las cifras de los graduados de carreras marítimas es un triste ejemplo: la oficina de POEA tiene registrados unos 550,000 marinos, pero al menos 300,000 están a la espera de conseguir un puesto de trabajo (Bernardi, 2005:4). Otra consecuencia posible es que la proliferación de programas para la formación de enfermeras puede desembocar en entrenamientos por debajo de las normas deseables, lo que implica graduados con mala formación que, quizá, no logren pasar el examen para obtener sus licencias profesionales. Los más exitosos logran salir pero, una vez que lo hacen, sus decisiones personales pueden tener repercusiones en la sociedad en general. En el caso de la migración de enfermeras, hay algunos reportes de hospitales 
provinciales o clínicas rurales que han tenido que cerrar o que se encuentran al borde de ser clausuradas debido a la salida de las enfermeras. Las grandes cantidades de enfermeras que salen del país han revivido las discusiones en torno a cómo controlar esa emigración, incluida la medida de imponer el servicio obligatorio. Al mismo tiempo, el gobierno ha estado cabildeando, ante Estados Unidos, para que se incluya a Filipinas como un centro para la aplicación de pruebas del sistema NCLEX.

Se han generado discusiones similares en relación con los pilotos y mecánicos de las aerolíneas, quienes han sido pirateados por las compañías aéreas extranjeras (Flores, 2006). Por una parte, se ha propuesto que se imponga una moratoria para la salida de estos profesionales calificados, pero, por la otra, también se ha reconocido el derecho de los individuos a buscar empleo en el extranjero. Una solución en el corto plazo, propuesta por el Departamento del Trabajo y el Empleo, es establecer como requisito que los trabajadores que salgan informen a sus patronos con seis meses de anticipación en vez de hacerlo sólo un mes antes. Ello retrasaría la salida de quienes aspiren a convertirse en migrantes, pero eventualmente acabarían por salir.

El anuncio, por parte del gobierno, de enviar un millón de trabajadores filipinos al extranjero cada año constituye una medida de política sin precedentes y una clara divergencia respecto al espíritu de la Secc 2 (c) de la ley RA 8042. Este objetivo también se menciona en el plan de desarrollo a mediano plazo (2004-2010). La declaración de la ex secretaria del Trabajo, Patricia Santo Tomás, en el informe anual (2001) de la POEA (que fue repetida en los reportes de 2002, 2003 y 2004) presagia un énfasis en el desarrollo del mercado:

[...] Solíamos preocuparnos principalmente por el bienestar. Pienso que en la mayoría de los países del mundo, aun cuando el bienestar es todavía una preocupación central, se ha elevado significativamente el estándar del cuidado que se ofrece a nuestros compatriotas. Lo que probablemente necesitemos ahora es enfocarnos más en la mercadotecnia [cursivas nuestras] y en cómo asegurar que la salida de nuestros trabajadores pueda realizarse de manera más ágil, mejor y con el menor costo para ellos. Probablemente también deberíamos establecer las reglas para lograr responder muy rápidamente a las demandas del mercado (Reporte Anual, POEA, 2001: 1).

Hubo grandes expresiones de júbilo, en el Departamento del Trabajo y el Empleo, cuando se alcanzó la marca del millón de trabajadores en el extranjero, en noviembre de 2006. El reto para Filipinas consiste en reflexionar larga y profundamente acerca de la manera en que la migración internacional puede convertirse en un instrumento para el desarrollo sostenible. Es claro que Filipinas tendrá que ir más allá de la orientación hacia el envío de mano de obra en su perspectiva de la migración internacional. Ello requerirá, sobre todo, la integración de escenarios de la migración internacional en la planeación del desarrollo. Las tendencias en la migración de mano de obra y de trabajadores calificados deben considerarse a la luz de un plan de desarrollo de los recursos humanos y han de desarrollarse las acciones adecuadas para abordar las necesidades presentes y futuras. La orientación profesional o vocacional en la educación media ha 
de fortalecerse para ayudar a los jóvenes a decidir en torno a sus carreras y planes de vida. Podrían ofrecerse programas de becas o subsidios a los estudiantes que pasen por cursos o entrenamientos de especialidades con escasa disponibilidad. Esto implica que se monitoreen las instituciones académicas y de entrenamiento para asegurar que ofrezcan educación de calidad.

El Estado también necesita explorar los prospectos para la cooperación en programas de desarrollo que lo hagan interactuar con los países receptores que dependen de los trabajadores y del personal calificado proveniente de Filipinas. Deben establecerse las líneas de las políticas y programas para el retorno y la reintegración de los ofw's, los lazos con los filipinos calificados en el extranjero y con altos niveles de entrenamiento así como la transferencia de conocimientos y recursos. En lo que se refiere a la población de la diáspora, Filipinas debería continuar y fortalecer las buenas prácticas ya iniciadas en el área de protección a los migrantes. La cooperación con las ONG’s orientadas a los migrantes, las organizaciones religiosas y las asociaciones de migrantes ha de buscarse y fortalecerse. Se requieren más estudios acerca de la manera en que las asociaciones de migrantes se forman (o se disuelven), sus vínculos transnacionales con el país de origen, la manera en que pueden ser socios en el desarrollo y de qué modo el Estado puede desempeñar un papel más positivo en las transferencias de las contribuciones, al país, de los filipinos en el extranjero. Filipinas también puede beneficiarse de las experiencias de otros países de origen y de su vinculación con sus diásporas para generar desarrollo en el país de origen, como en el programa mexicano del Tres por Uno para la cooperación entre los migrantes y sus contrapartes en el gobierno, el éxito de Taiwán para revertir la fuga de cerebros y otros ejemplos pueden ofrecer algunas valiosas ideas en torno a las posibilidades y perspectivas más activas y frescas.

\section{BIBLIOGRAFÍA}

ABella, Manolo (1995), "Asian Labour Migration: Past, Present and future», ASEAN Economic Bulletin, 12(2), pp. 125-138.

(1978), «Labor Administration and Development in Filipinas», Philippine Labor Review, 3(2), pp. 21-50.

abubakar, Carmen (1999), «mnlf Hijrah: 1974-1996», Asian and Pacific Migration Journal, 8(1-2), pp. 209-221.

Aguilar, Filomeno Jr. (2000), «Nationhood and Transborder Labor Migrations: The Late Twentieth Century from a Late Nineteenth Century Perspective», Asian and Pacific Migration Journal, 9(2), pp. 171-198.

ASIs, Maruja (2006a), «Filipinas' Culture of Migration», Migration Information Source, www.migracióninformation/Resources/philippines.cfm, consultado el 10 de abril de 2006.

(2006b), «Living with Migration: Experiences of Left-behind Children in Filipinas», Asian Population Studies, 2(45-68).

(2006c), «International Migration and Development in Filipinas», en Kristof Ta- 
mas y Joakim Palme (eds.), How Migration Can Benefit Development, Institute for Futures Studies, Stockholm.

(2005a), «Recent Trends in International Migration in Asia and the Pacific», Asia-Pacific Population Journal, 20(3), pp. 15-38.

(2005b), «Caring for the World: Filipino Domestic Workers Gone Global», en Shirlena Huang, Brenda S.A. Yeoh y Noor Abdul Rahman (eds.), Asian Women as Transnational Domestic Workers, Marshall Cavendish Academic, Singapur.

(2005c), «The Filipinos in Sabah: Unauthorised, Unwanted and Unprotected», en Santosh Jatrana, Mika Toyota y Brenda S.A. Yeoh (eds.), Migration and Health in Asia, Routledge, Londres y Nueva York.

(2005d), «Understanding International Migration in Asia», en Fabio Baggio (ed.), Exodus Series 1, A Resource Guide for the Migrant Ministry in Asia, Scalabrini Migration Center, Quezon City.

(2004), «Unwrapping the Balikbayan Box: Overseas Filipinos and the Homeland», Paper presented at the International Conference on State-Diaspora Relations, Ciudad de México, octubre 2004.

(2001), «The Return Migration of Filipino Women Migrants: Home But Not for Good?» en Christina Wille y Basia Passl (eds.), Female Labour Migration in South-East Asia, Asian Research Centre for Migration, Chulalongkorn University, Bangkok.

BAGgio, Fabio y Maruja M.B. Asis (2006), «Global Workers, Local Philanthropists: Filipinos in Italy and the Tug of Home», Reporte, Scalabrini Migration Center.

Battistella, Graziano (1995), «Philippine Overseas Labour: From Export to Management», ASEAN Economic Bulletin, 12(2), pp. 257-274.

Battistella, Graziano y Maruja M.B. Asis (eds.) (2003), Unauthorized Migration in Southeast Asia, Scalabrini Migration Center, Quezon City.

BERnARDI, Savino (2006), «The Pastoral Care of Seafarers», en Fabio Baggio (ed.), Exodus Series: A Resource Guide for the Migrant Ministry in Asia, op. cit.

Canuday, Jowel (2006), «The Power of the Displaced», Asian and Pacific Migration Journal, 15(1), pp. 115-136.

CASTLEs, Stephen y Mark Miller (2003), The Age of Migration, $3^{\text {era }}$ edición, The Guilford Press, Nueva York y Londres.

COMmission on filipinos overseas (2002), Handbook for Filipinos Overseas, Commission on Filipinos Overseas, Manila.

EPISCOPAL COMMISSION ON MIGRANTS AND ITINERANT PEOPLE/APOSTLESHIP OF THE SEA-MANILA, SCALABRINI MIGRATION CENTER AND OVERSEAS WORKERS WELFARE ADMINISTRATION (ECMi/AOS-MANILA, SMC y OWWA) (2004), Hearts Apart: Migration in the Eyes of Filipino Children, www.smc.org/ph/heartsapart.html.

flores, Alena Mae S. (2006), «Pilots' Exodus Endangering RP Aviation Industry?», Manila Standard Today, 22 March 2006, www.manilastandardonline. com/?page=business02_mar22_2006, consultada el 28 de abril de 2006.

global Commission on international migration (GCim) (2005), Migration in an Interconnected World: New Directions for Action, GCIM, Ginebra. 
HUGO, Graeme (2003), «Migration and Development: A Perspective from Asia», No. 14, IOM Research Series, International Organization for Migration, Ginebra.

MAAS, Marisha (2005), «Transnational Entrepreneurship: Exploring Determinants and Impacts of a Dutch-based Filipino Immigrant Business», Asian and Pacific Migration Journal, 14(1-2), pp. 169-192.

NACIONES UNIDAS (ONU) (2006), International migration and Development, Reporte del Secretario General ante la Asamblea General, Sexagésima Sesión, un A/60/8/71, 18 de mayo de 2006.

national statistical CoORdination bOARd (NSCB) (2006), The Philippine Countryside in Figures, Edición 2005, NSCB, Makati City.

opiniano, Jeremaiah (2005), «Filipinos Doing Diaspora Philanthropy: The Development Potential of Transnational Migration», Asian and Pacific Migration Journal, 14(1-2), pp. 225-241.

PHILIPPINe MigRANTS RightS WATCH (PMRW) (2003), The Rights of Filipino Migrants, Philippine Migrants Rights Watch, Manila.

Philippine overseas Employment administration (n.d.), Migrant Workers and Overseas Filipinos Act of 1995 (Republic Act No. 8042 and Its Implementing Rules and Regulations), Philippine Overseas Employment Administration, Mandaluyong City.

POWERs, Shawn (2006), «Bayanihan Across the Seas: Diaspora Philanthropy and Development in Philippines», Reporte realizado con apoyo del Fondo Fullbright.

wescott, C. (2006), «Harnessing Knowledge Exchange Among Overseas Professionals of Afghanistan, the People's Republic of China and Filipinas», www.unitarny. org/mm/File/ADB\%20knowledge\%20exchange.pdf, consultado el 23 de mayo de 2006. 